\title{
Field Days at the Rothamsted Experimental Station
}

$\mathrm{T}$ WO important meetings took place at Rothamsted on June 28 and 29 . The first was a gathering of Empire agricultural officers on leave in England who were visiting Rothamsted by the joint invitation of the Station and the Imperial Bureau of Soil Science.

This has now become a yearly function, and serves the double purpose of enabling Empire agriculturists to meet each other and acquaint themselves with recent work of the Station and the Soil Bureau. There was a full gathering, and no less than fifteen Empire countries were represented. The programme included a tour of the laboratories and field plots; and a brief summary of the work of the Station and the Soil Bureau was given by the Director.

The annual field inspection at Rothamsted was held on June 29, when the Right Hon. the Earl of Radnor, chairman of the Lawes Agricultural Trust, presided over a large gathering of friends and supporters of the Station. The guest of honour was the Right Hon. the Earl of Feversham, Parliamentary Secretary to the Ministry of Agriculture and Fisheries.

The morning was devoted to a visit to the famous field experiments, the Park grass plots showing the effects of fertilizers on meadow hay, and Broadbalk with its striking series of wheat plots. Broadbalk, now carrying its ninety-fifth successive crop of wheat, was in first-class order, and showed splendid standing crops where complete manuring had been given. Attention was not confined to the classical fields, and this year the guests were conducted over a modern grazing experiment on High Field carried out in co-operation with the Royal Agricultural Society of England. The purpose of this experiment is to evaluate the fertilizing effect of the residues left behind when concentrated feeding stuffs are fed to cattle at pasture. Tenant right valuers at present use the old and well-known tables of Hall and Voelcker in estimating the compensation due to an outgoing tenant arising from the consumption of concentrated foods on grass, and the present experiment will show whether in present conditions they still remain the most suitable basis, and if not, what should be done to replace them.

In his chairman's address, Lord Radnor stressed the importance of the work on soil fertility in which Rothamsted was engaged. With our shrinking cultivated area and the progressive exhaustion of virgin soils overseas a time would soon come when food production from our home soils would be a vital problem. Knowledge gained now and put in a form that farmers could readily use would serve to meet the demands that sooner or later would be made upon our agriculture. To make full use of its opportunities the Station equipment had to be brought completely up to date, and it was hoped to raise a sufficient sum to have this completed by the centenary, which would be celebrated in 1943 .

Speaking of the contribution of Rothamsted to agriculture, Lord Feversham acknowledged the assistance that the Ministry of Agriculture had received from the Station in connexion with the Land Fertility Scheme. The recent work carried out in pasture problems had been of great value in this connexion. He had pleasure in announcing that the Government had granted. $\$ 14,500$ to meet half the cost of the new wing to accommodate the Departments of Chemistry and Biology; while plant physiology was to be housed in a separate building. This money was well spent and would undoubtedly give a good return for the outlay. The taxpayer had frequently been called upon in recent years to make contributions to the agricultural industry. There should be no appearance of subsidizing obsolete methods. One of the functions of agricultural research was to ensure that farmers should have at their disposal trustworthy information on which to base efficient production.

Sir John Russell than gave a brief outline of the work of the Station. Agriculture was at present passing through a period of depression; some people were turning to politics and others to economics as a remedy for the present situation, but these fields were outside the scope of the Station's activities. The purpose of the Rothamsted work was to provide sound technical knowledge and put it out to farmers in such a way that costs could be lowered or output increased. The resources of the Station were amplified in two directions: In pure science the Rothamsted work was linked up with investigations in highly specialized fields; with Prof. V. H. Blackman, for example, in plant physiology, and with Sir William Bragg at the Royal Institution. On the other side, the Station owed much to the co-operation of expert users of agricultural produce. Thus the Institute of Brewing gave valuable help in the study of barley problems, and the experts of the Sugar Commission in the study of the production of sugar beet. Pro. gressive farmers all over Great Britain allowed the Station staff to carry out experiments on their land under conditions of actual agricultural practice.

\section{Processes of Urine Formation*}

\begin{abstract}
THE controversies which, in the past, have characterized the experimental literature on the nature of renal function have resulted in large part from lack of information concerning the composition of urine at different stages of its elaboration within the structural units of the kidney. The discovery that the kidneys of amphibians and of reptiles
\end{abstract}

* Substance of the Croonian Lecture delivered by Prof. A. N. Richards, University of Pennsylvania, before the Royal Society on June 30 . can be subjected to direct microscopic observation during life indicated that a way of obtaining such information might be found.

Microdissection methods, as developed by Barber, Kite and Chambers, applied to the kidneys of these animals, have made possible the collection of minute specimens of fluid from Bowman's capsule and from various levels of the uriniferous tubules. Quantitative analyses of these specimens show that with 